\title{
Lift-off characteristics and flame base structure of coal seeded gas jet flames
}

S R Gollahalli, BE, ME, MASc, PhD, PE, FASME, A Prasad, BS(Eng), MS(Eng), AASME and

$S$ Gundavelli, BS(Eng), MS(Eng)

School of Aerospace and Mechanical Engineering, University of Oklahoma, Norman, Oklahoma, USA

\begin{abstract}
An experimental study of the burner rim stability characteristics and the flame base structure of flames co-fired with pulverized coal and propane gas is presented. Lift-off and reattachment characteristics are examined as functions of propane concentration in the jet stream for lignite, bituminous and anthracite coals. The effects on flame base structure are studied in terms of temperature, product species concentration and radiation profiles. The addition of lignite and anthracite coals favours the lift-off transitions. Bituminous coal, on the other hand, makes the flame more stable. The peak values of temperature and concentrations of major combustion product species in the flame stabilization region strongly depend upon the rank of coal. Among the coals tested, bituminous coal produces the highest peak temperature and its flame emits maximum radiation from the stabilization region. Anthracite and lignite coals produce somewhat comparable stability characteristics and structure of the flame base. The effects of coal rank are explained by the differences in volatile matter, moisture and pyrolysis characteristics of coals.
\end{abstract}

Key words: flame stabilization, co-combustion, pulverized coal, flame structure, pollutants

\section{NOTATION}

$d \quad$ nozzle diameter

HV higher heating value

$L \quad$ lift-off distance

$r$ radial location

$u_{\mathrm{f}} \quad$ flame velocity

$u_{\mathrm{g}} \quad$ axial gas velocity

$w$ flame width at the base

$x$ axial location

$x_{\mathrm{p}} \quad$ propane molefraction

\section{INTRODUCTION}

In recent years, the high expense of capital equipment and the demands for energy resource conservation and environmental protection encourage multi-fuel capability of combustion systems, particularly those in the power generation industry. Co-firing of different quality fuels is the first step towards developing technologies that enable fuel switching and multi-fuel utilization in combustors without extensive modifications (1). Also, co-combustion is an important step which allows retrofitting of the existing devices until new generations of systems that have multi-fuel potential come into practice. Gas-fired incinerators of solid materials, cofiring of refuse-derived and other biomass fuels with coal, burning of tyres and plastics while enhancing their combustion with natural gas, and dual-fuel diesel engines are examples of co-firing technology (2-5). While reviewing coal combustion issues, Green and coworkers $(6,7)$ suggested the co-firing of coal with natural gas as an oil-conservation measure. They discussed the merits of co-firing of coal and coal-waterslurry fuels with gas, explaining the synergism of the approach (8). The possibilities of wider flame stability and mitigation of some problems inherent to coal combustion when coal was co-fired with oil have been indi-

The MS was received on 17 November 1995 and was accepted for publication on 10 May 1996. cated (1). By the same token, some deficiencies inherent to natural gas combustion, such as low radiation emission, can be remedied by employing co-firing with coal. This approach is promising, particularly when natural gas is used in the combustors designed for oil. Co-firing may be tailored to simulate the oil flame, especially in its radiating characteristics. In spite of its significant potential, controlled combustion studies on this subject are sparse; in particular the fundamental studies are highly limited. This paper describes a study of the combustion of one such hybrid fuel (a fuel gas, a diluent gas and a solid fuel). By having a combination of the fuel and diluent gases, a further flexibility of controlling flame characteristics such as temperature is offered. In the following, the burner rim stability and structure of the flame anchoring region of a fuel consisting of propane, nitrogen and pulverized coal is presented.

\subsection{Background of burner stability issues}

The lift-off and blow-out phenomena of gas jet flames have received a great deal of attention in recent years (9-13). Most of the studies have focused on the burner exit velocity as the primary variable. As the jet velocity affects the local flow field, flame lift-off caused by increasing burner exit velocity affects both the flow and chemical structure of the flame base region. Hence, the roles of fluid dynamic and thermochemical effects cannot be delineated. Prasad et al. (14) employed a method in which the lift-off phenomenon can be studied in terms of the reactant concentration in the jet fluid while keeping the burner exit velocity constant. That method is useful in isolating the effects of parameters like nozzle shape or additives in the jet stream by decoupling their influences from the accompanying effects of the jet exit velocity.

The literature contains several studies on the lift-off characteristics of homogeneous gas jet flames. However, the information on the stability of particle-seeded gas jet flames is limited in spite of their application in pulverized coal furnaces (PCF). In this study, a method 
similar to that used by Prasad et al. (14) is employed to study the effects of coal particles and their properties on the stability of pulverized coal seeded gas jet flames.

\section{EXPERIMENTAL}

Figure 1 is a schematic diagram of the experimental apparatus. The combustion chamber is made of thick steel plates with a square cross-section $(76 \mathrm{~cm} \times 76 \mathrm{~cm})$ and a height of $117 \mathrm{~cm}$. The chamber has air-cooled optically clear Pyrex windows $(92 \mathrm{~cm}$ long and $20 \mathrm{~cm}$ wide) on all four side walls. The burner assembly (Fig. 2a) mounted to the base plate of the combustion chamber consists of a contoured nozzle supported concentrically inside a $158 \mathrm{~mm}$ i.d. machined pipe. The nozzle consists of four parts: a divergent inlet section, a cylindrical settling chamber, a convergent contoured section, and an interchangeable nozzle tip. A diffusion flame of a mixture of nitrogen and propane in air was used to ignite and support the coal flame as in the previous studies $(15,16)$. Commercial grade propane and nitrogen were supplied from gas cylinders and metered with rotameters. Propane was supplied from a large cylinder that lasted for the entire investigation and ensured that the fuel composition remained the same. The gas was analysed with an infra-red analyser to ascertain its composition. Combustion air was supplied from an oil-less vane compressor through the annulus surrounding the burner tip. Turbulence in the combustion air stream was minimized and a uniform velocity profile at the plane of the fuel nozzle was generated by means of a honeycomb section and a set of screens in the annulus pipe. All gas flowrates were monitored by calibrated rotameters.

The coal feeding system (Fig. 2b) was designed to provide a steady flow of pulverized coal to the burner without compacting. The system consisted of a steel pipe, the contoured bottom edge of which meshed with a rotating shaft having a machined notch $(2 \mathrm{~cm}$ long, 1 $\mathrm{cm}$ wide and $0.65 \mathrm{~cm}$ deep) and driven by a variablespeed d.c. motor. Pulverized coal was stored in a polyvinyl chloride (PVC) pipe attached to the steel pipe. The PVC pipe was continuously vibrated to avoid compaction of the coal powder. Each time the notch in the rotating shaft meshed with the pipe a certain amount of coal was delivered to the fuel line. The fuel-gas mixture carried the coal to the burner. The coal flowrate was varied by adjusting the speed of the rotating shaft. The system was calibrated by filtering and weighing coal powder carried by the gas stream against the shaft speed. A complete description of the system is given by Gollahalli et al. (17).

Flame photography was performed using panchromatic colour and black and white films with a $35 \mathrm{~mm}$ camera. Both short (1/1000 second) and long (1 second) exposure photographs were taken. The exposure time and the type of film were kept the same in all experiments. Assuming that variations in processing the films with automatic commercial processors were minimal, the photographs were used to determine the changes in flame configurations. Because the jet flow and co-flow velocities were maintained constant, the interactions of jet flow and co-flow and vortex shedding that causes the oscillatory movement of the flame base could be

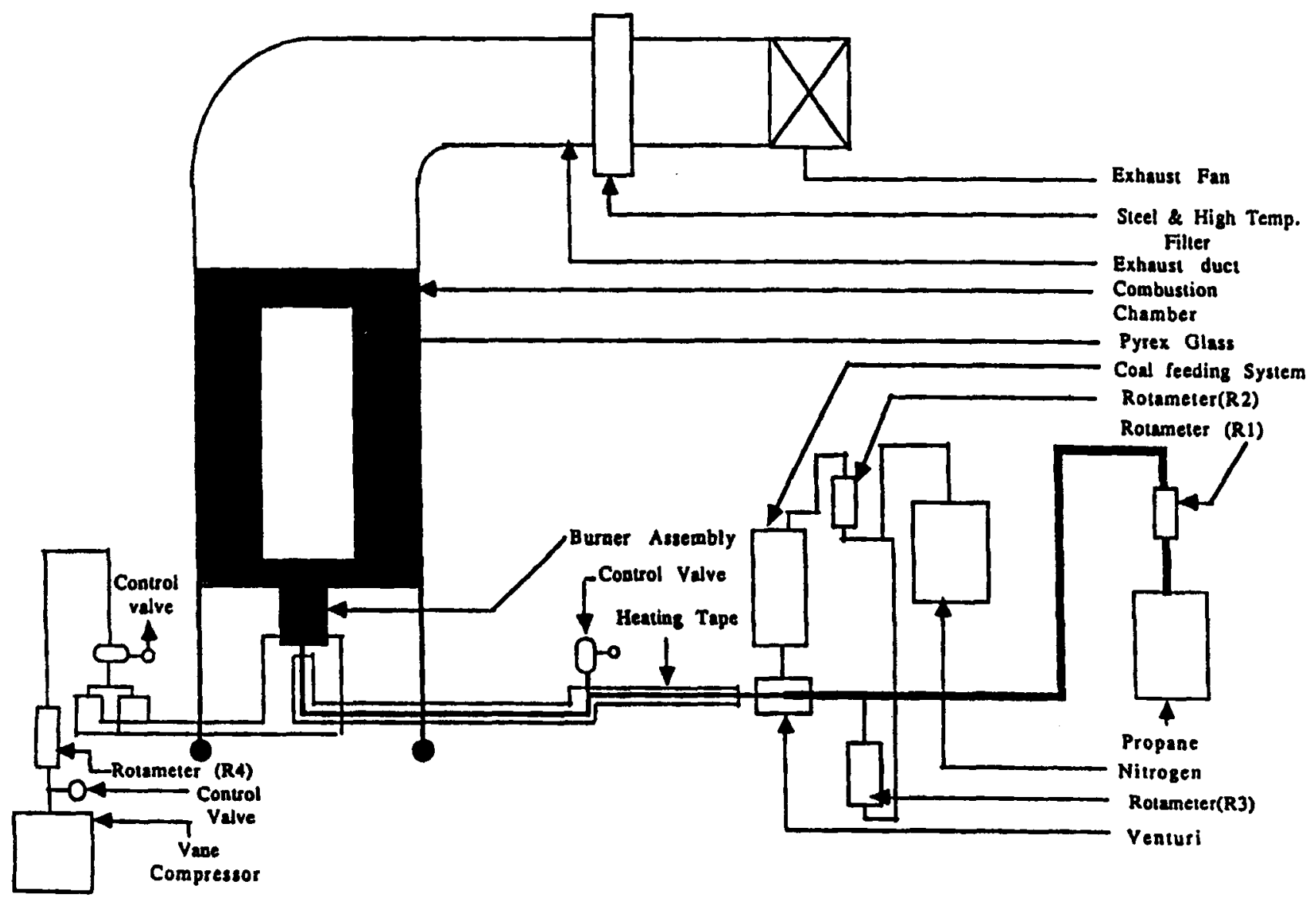

Fig. 1 Schematic diagram of the experimental apparatus 


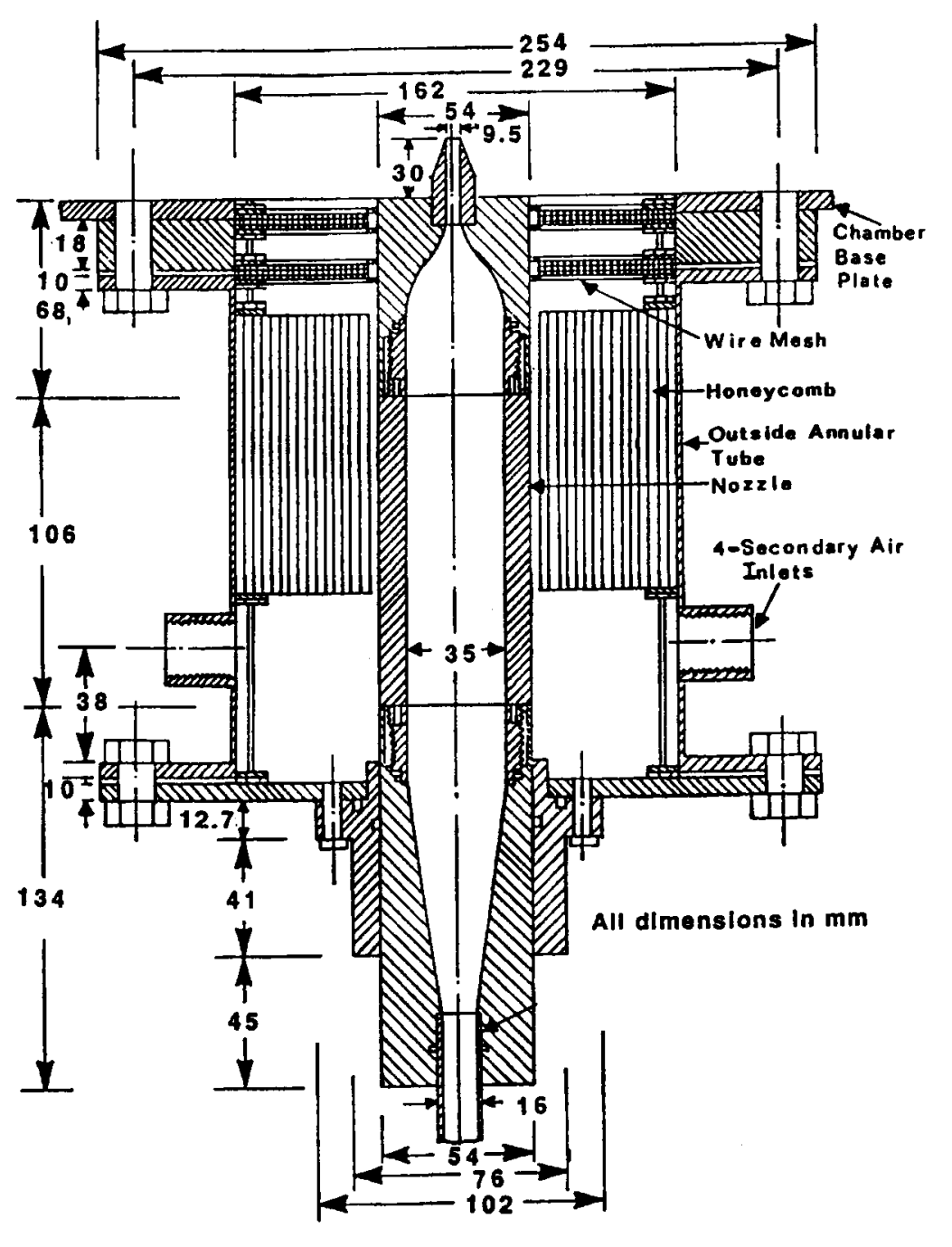

a

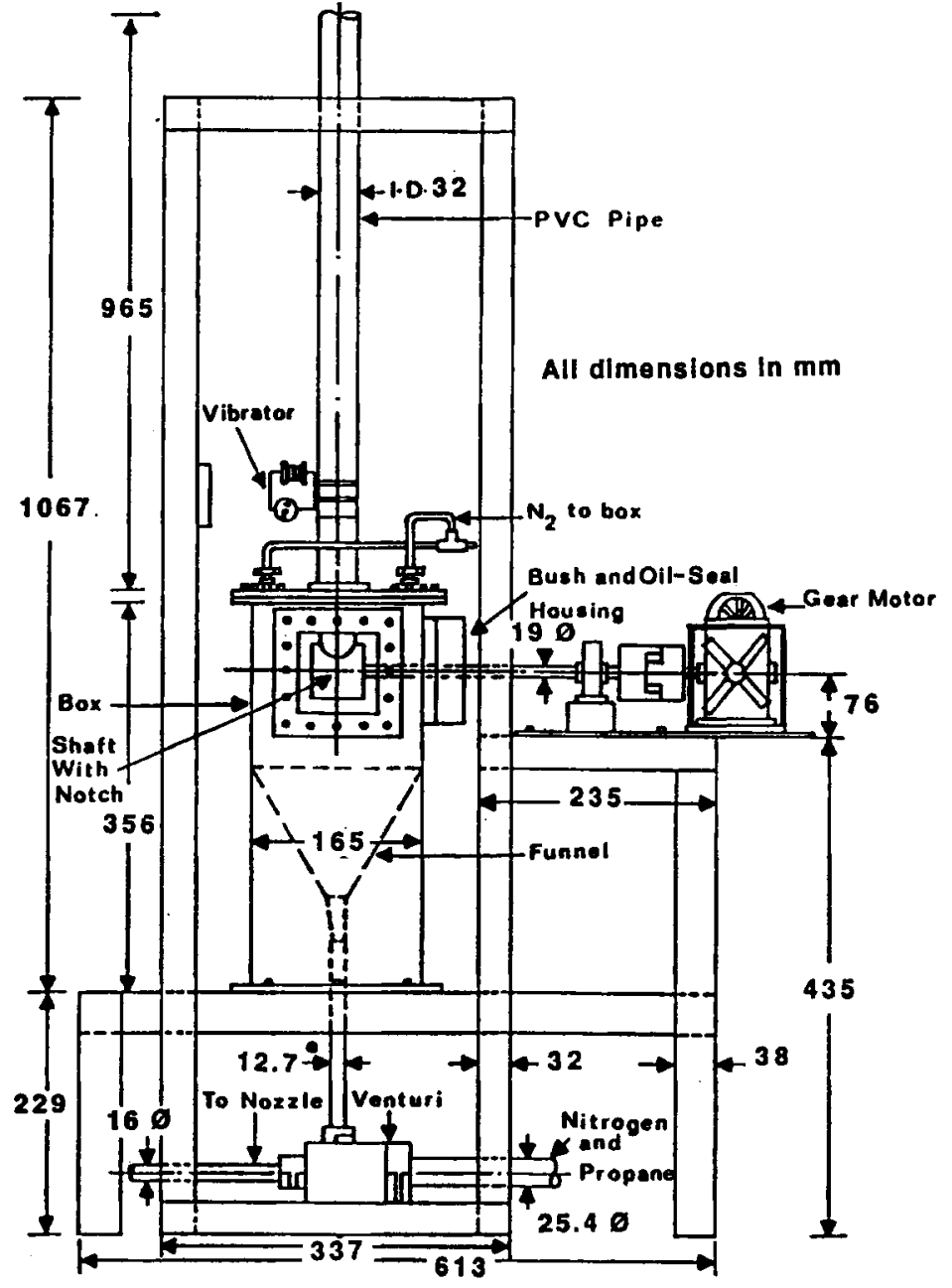

b

Fig. 2 Details of (a) the burner assembly and (b) the coal powder feed system 
Table 1 Experimental conditions

\begin{tabular}{ll}
\hline Burner tip diameter & $9.5 \mathrm{~mm}$ \\
Coal feed rate & $10 \pm 1 \mathrm{~g} / \mathrm{min}$ \\
Co-flow air velocity & $0.656 \mathrm{~m} / \mathrm{s}$ \\
Air temperature & $297 \pm 3 \mathrm{~K}$ \\
Fuel jet velocity & $6.5 \mathrm{~m} / \mathrm{s}$ \\
Propane mole fraction & $0.33-0.38$ \\
Coal mass fraction & 0.23 \\
Jet Reynolds number & \\
$\quad$ Without coal & $5150-5400$ \\
$\quad$ With coal & $6600-6800$ \\
\hline
\end{tabular}

assumed to remain constant. Hence, the one-second exposure photographs were considered to represent a reasonably averaged position of the flame base. The temperature in the flame was measured with a silicacoated platinum-platinum $13 \%$ rhodium thermocouple with an exposed junction of diameter $0.5 \mathrm{~mm}$. The thermocouple hot junction was very small compared to the width of the flame, and hence no visible fluid dynamic disturbances were noticed when the thermocouple was introduced into the flames. Temperature readings were corrected for radiation and conduction losses following the procedure given by Fristrom and Westenberg (18). A chemiluminescent analyser was used to determine the concentrations of nitric oxide in the gas samples drawn through a water-cooled $3.2 \mathrm{~mm}$ diameter stainless steel tube. The gas sample train consisted of a series of quartz glass wool filters to remove solid particulates and an ice-chilled moisture trap to remove the water content of the sample. A polarographic analyser and two infra-red detectors were used to determine the concentrations of oxygen, carbon monoxide and carbon dioxide respectively. To obtain a measure of uncertainty caused by the variations in flowrate and other experimental variables intended to be maintained constant, some experimental runs were repeated approximately 10 times and the error bar limits for 95 per cent confidence were calculated. Average standard deviations of 3 per cent in nitric oxide concentration data in pure gas flames and 7 per cent in coal-seeded gas flames were obtained from these measurements.
Coals of three ranks were used in this study: lignite, bituminous and anthracite. Table 1 shows the experimental conditions and Table 2 shows the properties and particle size distribution of coals.

\section{RESULTS AND DISCUSSION}

In all experiments pulverized coal was fed at a rate of $10 \pm 1 \mathrm{~g} / \mathrm{min}$ and the flowrate of the fuel-gas mixture was also kept constant so that the weight fraction of the coal was held at a constant value of 0.23 . The coal mass flowrate was frequently checked before igniting the jet with the filtering procedure mentioned previously, to ensure the accuracy of the calibration curve. Pulverized coal was prepared locally using a small laboratory-scale grinder and the size distribution of coal was adjusted by using the scientific standard sieves. Further, the samples of coal-laden gases were drawn isokinetically from the nozzle exit and microscopically examined to check the particle size distribution. The propane flowrate was gradually reduced while correspondingly increasing the nitrogen flowrate in the jet stream and maintaining the burner exit velocity constant. The concentration of propane in the jet stream was changed, which affected the reactivity of the jet stream mixture and the flame configuration. Thus, the concentration of propane could be taken as an indicator of the flame stability affected by the jet stream composition. The changes in flame configuration, lift-off height, flame base width and flame appearance were recorded. Radial profiles of temperature and major species concentrations were obtained.

\subsection{Lift-off characteristics}

Prasad et al. (14) found that the gas jet flames exhibited three stages of transition when the inlet stream was progressively diluted. The first stage involved a transition from the burner-attached flame base to a condition where the flame base was stabilized at 2-5 diameters away from the burner. The flow conditions at the base

Table 2 Properties of coals

\begin{tabular}{|c|c|c|c|c|c|}
\hline & \multicolumn{5}{|c|}{ Proximate analysis (mass \%) } \\
\hline & $\mathrm{H}_{2} \mathrm{O}$ & VM & FC & Ash & \\
\hline $\begin{array}{l}\text { Lignite } \\
\text { Bituminous } \\
\text { Anthracite }\end{array}$ & $\begin{array}{r}22 \\
5.36 \\
5.46\end{array}$ & $\begin{array}{l}32.7 \\
39.2 \\
3.84\end{array}$ & $\begin{array}{l}36.7 \\
52.5 \\
87.5\end{array}$ & $\begin{array}{l}8.7 \\
2.9 \\
3.2\end{array}$ & \\
\hline & \multicolumn{5}{|c|}{ Ultimate analysis (mass \%) } \\
\hline & $\mathbf{H}$ & $\mathrm{C}$ & $\mathbf{N}$ & $\mathbf{O}$ & $\mathbf{s}$ \\
\hline $\begin{array}{l}\text { Lignite } \\
\text { Bituminous } \\
\text { Anthracite }\end{array}$ & $\begin{array}{l}3.9 \\
4.96 \\
2.1\end{array}$ & $\begin{array}{l}55.2 \\
73.8 \\
94.7\end{array}$ & $\begin{array}{l}0.93 \\
1.68 \\
0.8\end{array}$ & $\begin{array}{l}28 \\
8.75 \\
1.6\end{array}$ & $\begin{array}{l}0.83 \\
2.27 \\
0.8\end{array}$ \\
\hline Anthracite & \multicolumn{3}{|c|}{ Pyrolysis temperature* $(\mathrm{K})$} & Heating value & \\
\hline \multirow[t]{3}{*}{$\begin{array}{l}\text { Lignite } \\
\text { Bituminous } \\
\text { Anthracite }\end{array}$} & & \multicolumn{2}{|c|}{$\begin{array}{l}680 \\
571\end{array}$} & $\begin{array}{l}18.8 \\
31.2 \\
34.4\end{array}$ & \\
\hline & \multicolumn{5}{|c|}{ Size distribution for all coals (mass \%) } \\
\hline & & \multicolumn{2}{|c|}{$\begin{array}{c}75-150 \mu \mathrm{m} \\
45-75 \mu \mathrm{m} \\
<45 \mu \mathrm{m}\end{array}$} & $\begin{array}{l}50 \\
30 \\
20\end{array}$ & \\
\hline
\end{tabular}

$\overline{\mathrm{VM}}=$ volatile matter, $\mathrm{FC}=$ fixed carbon, $\mathrm{H}=$ hydrogen, $\mathrm{H}_{2} \mathrm{O}=$ moisture, $\mathrm{C}=$ carbon, $\mathrm{N}=$ nitrogen, $\mathrm{O}=$ oxygen, $\mathrm{S}=$ sulphur.

* Pyrolysis temperature is determined by differential scanning calorimeter. 
were laminar and the flame base was axisymmetric with sharp edges. A thin blue flame zone existed near the edges. This configuration was termed the lifted flame with laminar base by Prasad et al. (14). At a higher mole fraction of the diluent, the flame base suddenly jumped to a location 10-20 diameters away from the burner and the flame base had a jagged configuration. The flow near the flame base was turbulent and the flame was noisier. Prasad et al. (14) denote this configuration as the lifted flame with turbulent base. Photographs of gas jet flames and the flames of gas seeded with coal (bituminous) in these three configurations are shown in Fig. 3.

Figure 4 shows a comparison of the stabilty characteristics of the pure gas jet flame and the gas jet flame with three ranks of pulverized coals in the feed stream. It is noticed that the general trends of the lift-off characteristics do not markedly depend upon the presence or the type of coal in the feed stream. The critical values of the mole fraction and the magnitudes of the flame stand-off distance $(L)$ and the flame base width $(w)$, listed in Table 3, however, depend upon the presence and the type of coal.

In the previous study (14), it was shown that the liftoff behaviour of gas jet flames could be explained in terms of the local gas velocity $\left(u_{\mathrm{g}}\right)$ and flame velocity $\left(u_{\mathrm{f}}\right)$. The addition of coal particles affects both these velocities. Possible effects that could change the flame velocity $u_{\mathrm{f}}$ are: (a) coal particles introduce turbulence in

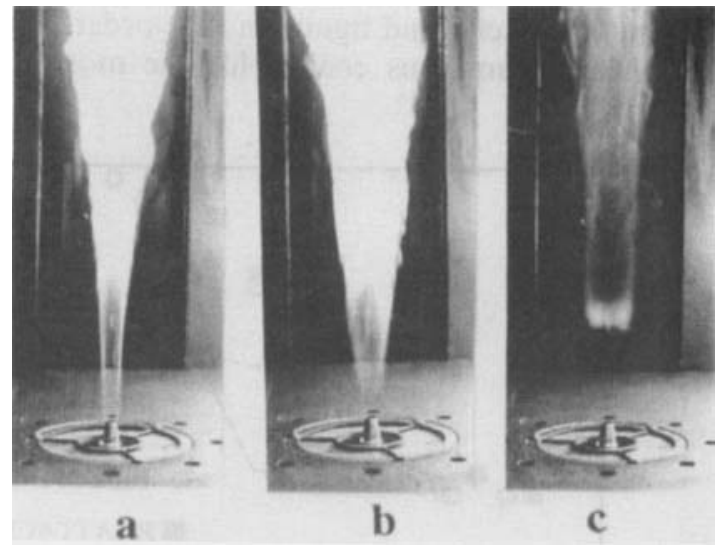

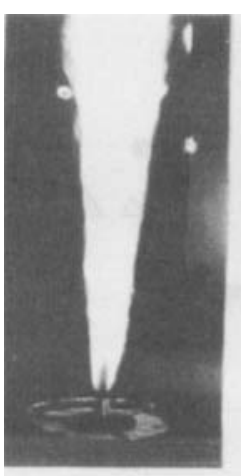

d

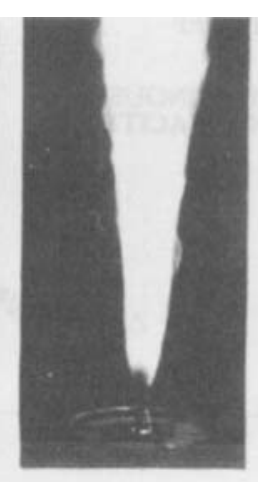

e

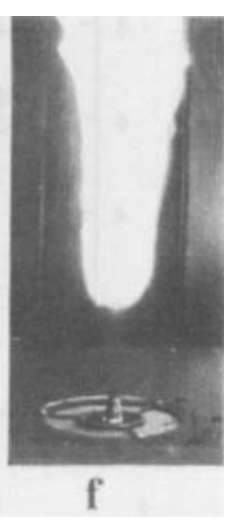

Fig. 3 Photographs of the gas jet $(a, b, c)$ and gas jet + coal (d, e, f) flames; (a) burner attached, (b) lifted with laminar base, (c) lifted with turbulent base

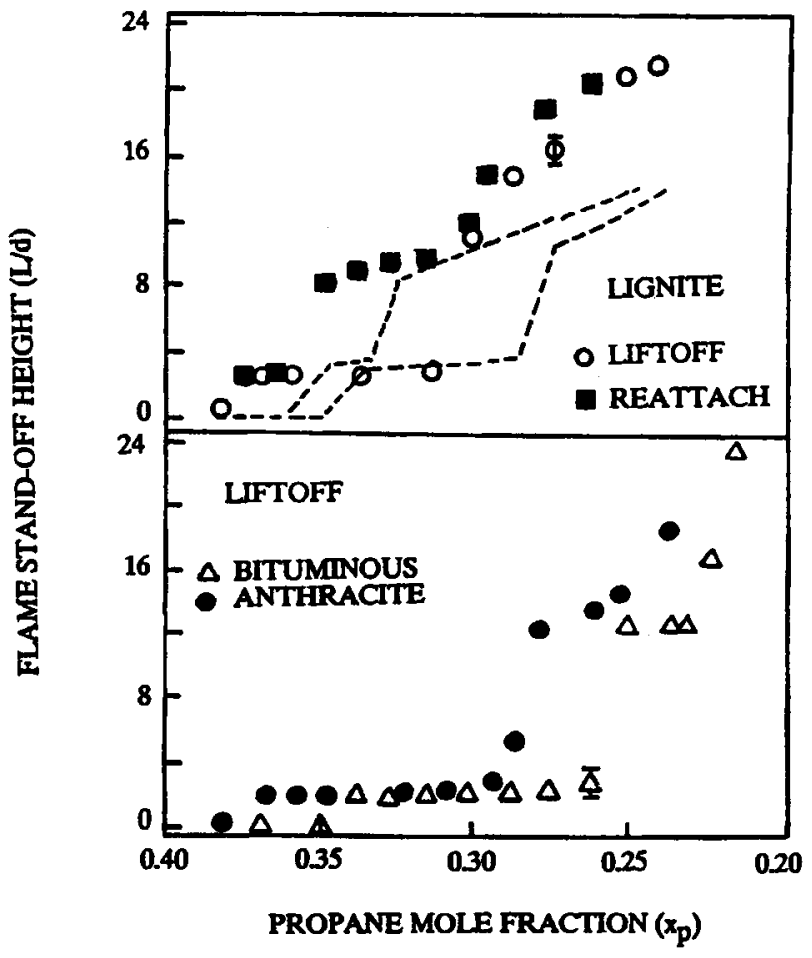

Fig. 4 Stability characteristics of the gas jet flame and gas jet flame co-fired with coals of different ranks

the flame base and increase $u_{\mathrm{f}}$, (b) moisture in the coal reduces flame temperature and thus decreases $u_{\mathrm{f}}$, (c) inert gases released upon pyrolysis of coal reduce $u_{\mathrm{f}}$ through decreases in both the concentrations of reactive species and temperature, (d) reactive species released upon devolatilization of coal, on the other hand, increase $u_{\mathrm{f}}$ and (e) the sensible heat required to raise coal particles to their pyrolysis temperature and endothermicity of pyrolysis reactions reduce combustion temperature and $u_{\mathrm{f}}$. The local gas velocity $u_{\mathrm{g}}$ may change because of (a) the additional volume of coal introduced, (b) agglomeration of coal powder into large particles, which could act as flame stabilizers, and (c) the release of moisture and volatiles upon pyrolysis. The calculations of the change in velocity show, however, that factor (a) is negligible. Depending upon the composition of coal, different characteristics dominate, as discussed in the following.

\subsubsection{First transition}

Of the three coals tested, lignite has the highest moisture content (Table 1). Because of a short flame lift-off distance and the consequent small residence time upstream of the flame base after the first transition, the

Table 3 Critical values of propane mole fraction, flame stand-off distance and flame base width at transition points

\begin{tabular}{|c|c|c|c|c|c|c|}
\hline \multirow[b]{2}{*}{ Fuel } & \multicolumn{3}{|c|}{ After first transition } & \multicolumn{3}{|c|}{ After second transition } \\
\hline & $x_{p}$ & $L / d$ & $\mathbf{w} / \mathbf{d}$ & $x_{p}$ & $L / d$ & $w / d$ \\
\hline Gas & 0.34 & 2.7 & 1.62 & 0.28 & 10.3 & 3.6 \\
\hline Lignite + gas & 0.37 & 1.84 & 1.42 & 0.30 & 10.8 & 5.1 \\
\hline Bituminous + gas & 0.34 & 2.1 & 1.77 & 0.25 & 17.9 & 6.6 \\
\hline Anthracite + gas & 0.36 & 1.94 & 1.61 & 0.28 & 11.3 & 3.4 \\
\hline
\end{tabular}


amount of reactive volatiles released is small and not enough to compensate for the effect of the large moisture content on $u_{\mathrm{f}}$. Although the release of water vapour increases the local gas velocity, the effect is linear and much weaker than the power-law dependence of $u_{\mathrm{f}}$ on concentrations (19). The net result is to decrease $u_{\mathrm{f}}$ more than the increase in $u_{\mathrm{g}}$ and thus lift-off occurs at a higher propane content $\left(x_{p}=0.37\right)$ of the jet fluid.

The first transition with anthracite coal occurs at $x_{\mathrm{p}}=0.36$. The pyrolysis temperature for anthracite is high and its volatile and moisture contents are low. Thus, the amount of anthracite undergoing pyrolysis over the flame lift-off distance is small, but the sensible heat required to raise the coal particles to the pyrolysis temperature is high. Anthracite particles in this region essentially act as inert particles which absorb and radiate energy. The net effect is to decrease $u_{f}$ and change $u_{\mathrm{g}}$ very little. Consequently, anthracite addition causes the first transition at a higher $x_{p}$ than in the gas flame. However, compared to lignite coal, the factors causing dilution are weaker, and hence the first transition occurs at a lower propane mole fraction in the inlet stream.

For bituminous coal the first transition occurs at $x_{p}=0.34$. Moisture content is low, but volatile contents, particularly the reactive components, are higher in this coal. It also has a lower pyrolysis temperature. Hence, the degree of pyrolysis and the amounts of reactants are higher with this coal. Their effect is to counteract the effects of sensible heat abstraction and endothermic effects of pyrolysis. Thus, the flame can withstand a lower value of propane mole fraction before the first transition occurs. These results corroborate the data on lean flammability limits of pulverized coal concentration reported by Hertzberg et al. (20). In the experiments of reference (20) in a constant volume reactor, the measured lean concentration limits of dusts varied inversely with their combustible volatile contents. For instance, at comparable conditions, the lean limits of bituminous and anthracite coals were $130 \pm 10$ and $450 \pm 50 \mathrm{mg} / 1$. In accordance with the above-stated arguments, the dusts having higher combustible volatile content, such as bituminous coal, can withstand lower lean limits or require a lower amount of the co-fired higher-grade gaseous fuel before the flame lifts off the burner.

\subsubsection{Second transition}

The second transition occurs (Table 3) with lignite, bituminous and anthracite coals at $x_{p}$ equal to 0.30 , 0.25 , and 0.28 respectively. Here, again, it is seen that bituminous coal allows the highest dilution, implying that it yields the stablest burner-attached flame. As the flame base is seen to be turbulent at this transition, the relevant flame velocity comprises both fundamental laminar flame velocity and the contribution due to turbulence. The fundamental flame velocity, a thermochemical parameter, increases with temperature (21). However, the turbulence intensity, which depends upon the local Reynolds number, decreases because of the increase in viscosity when the temperature is higher (19). With lignite addition, moisture release and heat abstraction decrease flame velocity due to their effect through flame temperature and concentration. However, as the flow at the flame base is already turbulent, the coal addition does not change the mixing levels markedly. Hence, the second transition with lignite occurs at a higher propane mole fraction than in the pure gas flame. On the other hand, anthracite coal addition decreases flame velocity due to higher heat abstraction. The effect, however, is weaker than that of lignite because of negligible moisture release in this case. With bituminous coal addition, the higher volatile matter and the reactive species fraction released on pyrolysis are higher than with the other two coals. Consequently, the flame base can withstand a much lower value of $x_{p}$ than with other coals before the second transition.

Bradley et al. (22) measured burning velocities in a methane-air-coal dust mixture in a premixed laminar flame burner. Their results, which agree well with the computational predictions, also show that the burning velocity $u_{\mathrm{f}}$ increases with the increase of combustible volatile content and $H / C$ mass ratio of coals. Because of the highest combustible volatile content of the bituminous coal, the contribution of the gaseous components released upon pyrolysis to $u_{\mathrm{f}}$ should be the largest, and hence the requirement of the co-fired gas to prevent the flame transition should be the lowest in that case. Experimental results indeed support that argument.

\subsection{Flame stand-off distance and base width}

From Fig. 5 and Table 3, it is seen that bituminous coal has the highest flame stand-off distance and base width, followed by anthracite and lignite in that order. As discussed earlier, bituminous coal yields the most stable

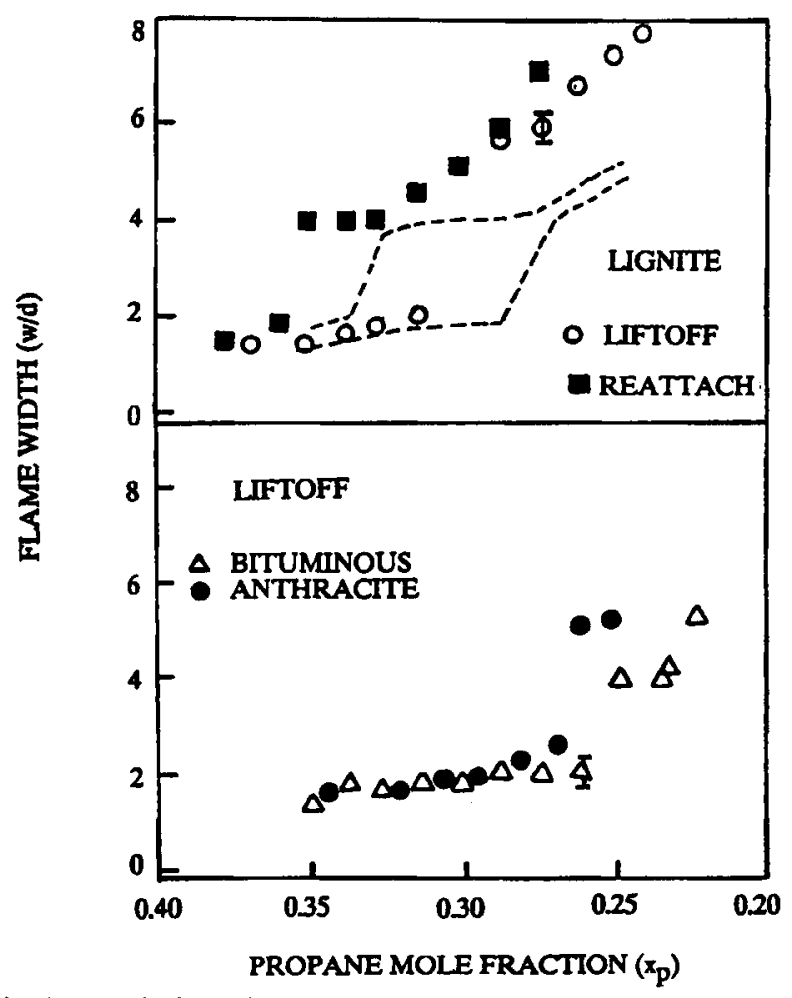

Fig. 5 Variation of flame base width with propane mole fraction in the jet stream in flames co-fired with propane and pulverized coals of different rank 
flame among the three coals tested, and hence it withstands the movement of the flame base to the farthest location before the balance between $u_{\mathrm{g}}$ and $u_{\mathrm{f}}$ breaks down. The lignite coal seeded flame is most prone to transitions and consequently the transitions occur closest to the nozzle with the smallest base width. Logically the values of flame stand-off distance and base width of anthracite seeded flames fall intermediate to those of lignite and bituminous coal seeded flames.

\subsection{Reattachment and hysteresis characteristics}

When the propane mole fraction is gradually decreased, the lift-off distance and flame base width increase. However, they do not retrace their path when the value of $x_{p}$ is increased. Similar to pure gas flames (13) they exhibit hysteresis. As the fluid dynamics and the shear layer structure at the burner exit remain qualitatively the same as in gas flames, this result is expected. The hysteresis was attributed to the difference between the characteristics and development of large-scale coherent structures in the near-burner flow field of attached and lifted flames. In the lifted flame, the flow over the flame stand-off distance behaves essentially as in a cold jet forming the large-scale vortex structures, whereas in an attached flame the hot reaction zone enveloping the jet suppresses the formation of large-scale structures (23, 24). The presence of the large-scale coherent structures and the entrainment changes caused by them oppose the movement of the flame base towards the burner and delay the reattachment of the flame to the burner. Recently, the flow visualization and laser velocimetry studies of a two-dimensional shear layer with and without coal particles in one of the flow streams have shown that the coal particles of the size range used in this study do not markedly alter the growth rate of the shear layers (25), which explains the similarity of the reattachment process between the pure gas jet and particle-seeded gas jet flames. For clarity, the reattachment process of only lignite is shown in Fig. 5. The reattachment profiles for anthracite and bituminous coals are given in references (17) and (26) and those profiles are similar to that shown for lignite.

\subsection{Radial temperature profiles in the flame base}

The radial temperature and composition profiles were measured at the base region of the gas flames with and without the addition of pulverized coals to the jet stream. Here, in order to compare the effect of adding coal to the gas stream and to diagnose the effects of coal rank on flame lift-off behaviour, only the profiles in the flame base after the first transition are given. The full set of profiles including those in the burner-attached flames are given in references (17) and (26). At the conditions for which the profiles are given here, the jet velocity, co-flow air velocity and coal mass fraction were kept constant at $6.5 \mathrm{~m} / \mathrm{s}, 0.66 \mathrm{~m} / \mathrm{s}$ and 0.23 . The jet exit Reynolds numbers accounting for the presence of coal varied only over a narrow range of 6590-6720 under these conditions.

The effects of the addition of pulverized coal and the rank of coal on radial temperature profiles are shown in Fig. 6. It is noticed that the addition of coal does not significantly change the shape of the temperature profile

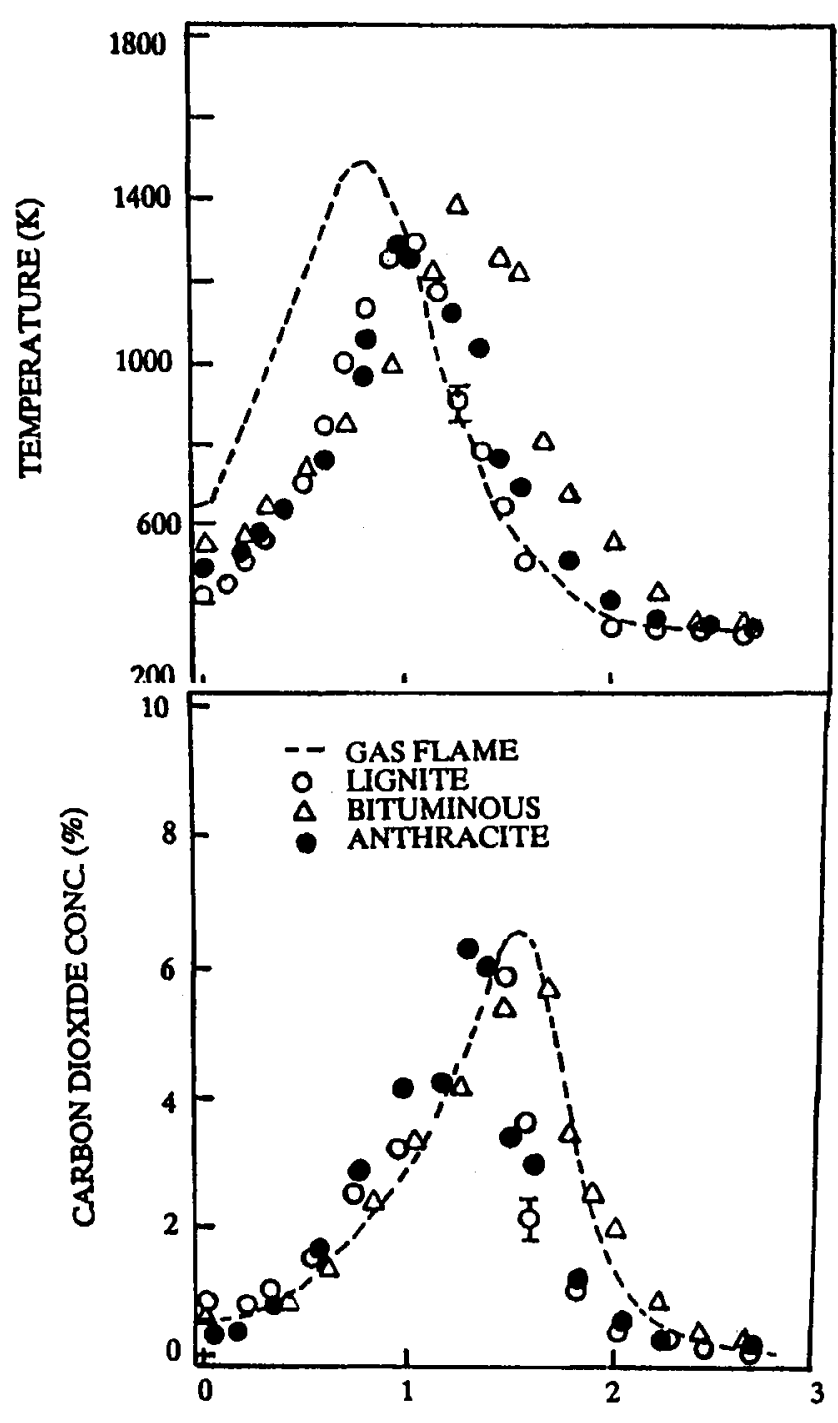

RADLAL DISTANCE (r/d)

Fig. 6 Radial profiles of temperature and carbon dioxide concentration in the base region of gas and pulverized coal seeded gas flames

in the flame stabilization region. However, the location and magnitude of the peak are shifted. The values of peak temperature (and their radial locations) in the flames with the addition of lignite, bituminous and anthracite coals are $1290 \mathrm{~K}(r / d=0.72), 1374 \mathrm{~K}(r /$ $d=1.28)$ and $1300 \mathrm{~K}(r / d=1.01)$ respectively, compared to $1436 \mathrm{~K}(r / d=0.69)$ for the pure gas flame without coal addition at similar conditions.

It is seen that the addition of coal to the gas flame decreases the peak flame temperature and shifts its location radially outwards. The probable reasons are: (a) absorption of sensible heat to raise the particles to their pyrolysis temperature, (b) endothermicity of devolatilization and pyrolysis reactions of pulverized coal and (c) enhanced radiation emission from solid particles. It is also noticed that the bituminous coal produces the highest temperature in the flame stabilization region among all the coals tested. The values of peak temperature are in conformity with the results of devolatilization study of Seeker et al. (27) and Mclean et al. (28). The volatile matter evolved from bituminous coals contains heavy hydrocarbons, while that from lignite is 


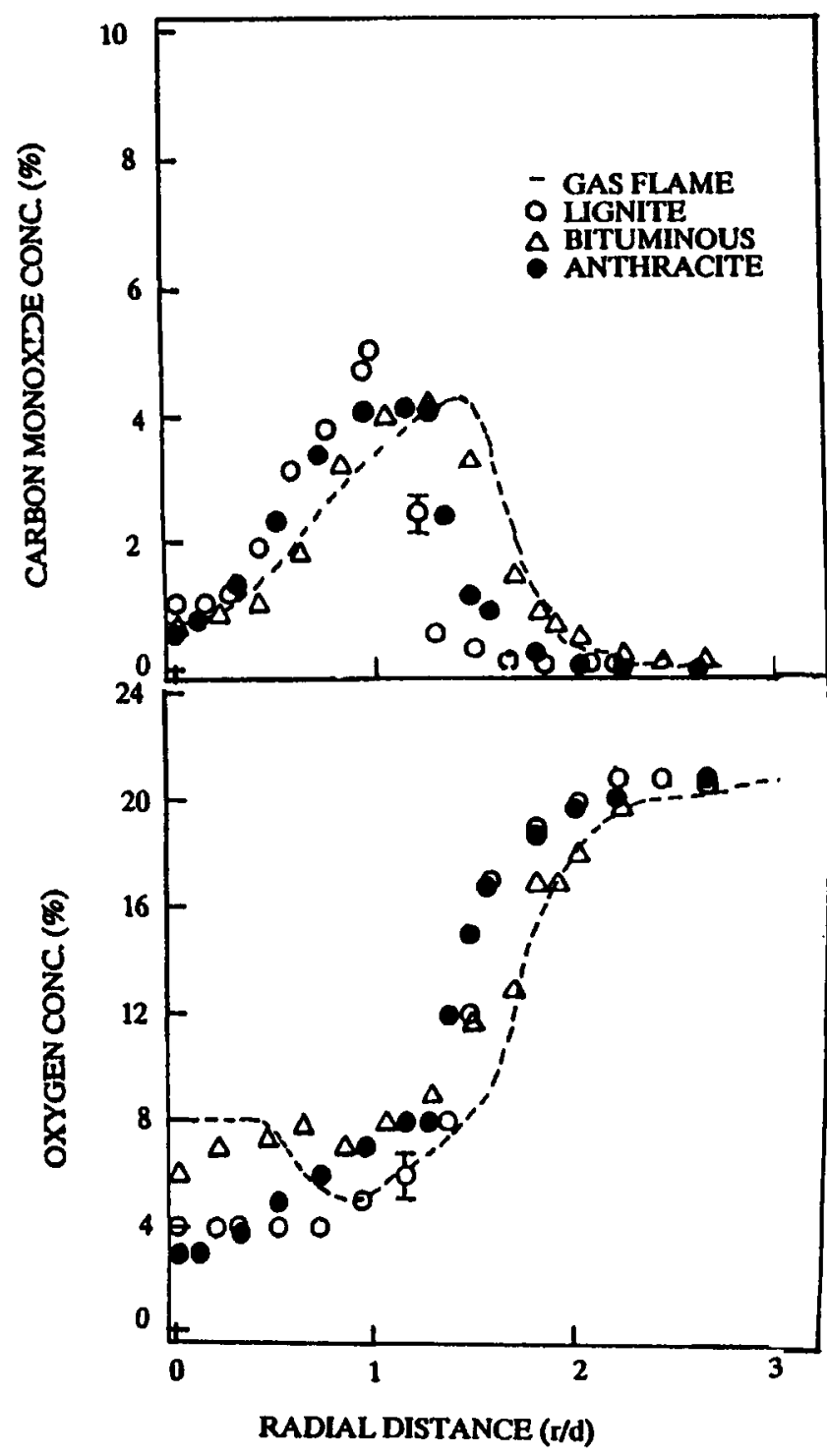

Fig. 7 Radial profiles of carbon monoxide and oxygen concentrations in the base region of gas and pulverized coal seeded gas flames

largely composed of $\mathrm{CO}_{2}, \mathrm{CO}$ and light hydrocarbons. The heating values of the volatiles produced from lignite coals are lower than those produced from bituminous coals. Anthracite has a lower volatile content, and hence, it does not contribute to the additional energy release at the flame stabilization region. This factor accounts for the very small difference of peak temperatures in the stabilization region of anthracite and lignite added flames. However, anthracite particles do contribute to higher radiation loss and hence the peak temperature is lowered in a gas jet flame when anthracite is added. Bradley et al. (22) conclude that the maximum temperature of $\mathrm{CH}_{4}$-air-graphite and coal dust-air flames is approximately $1550 \mathrm{~K}$ at the lean flammability limit. Accounting for the differences in the size range of particles, which is higher in the present study, the temperature data in the flame base near transition agree with reference (22).

\subsection{Composition profiles in the flame stabilization region}

The concentration profiles of oxygen, carbon monoxide and carbon dioxide along the radial direction in the flame base after the first transition are shown in Figs 6 and 7. Again, it is noticed that the general trends are not drastically altered by the addition of pulverized coal. The following emerge as points of interest. The peak concentrations of $\mathrm{CO}$ and $\mathrm{CO}_{2}$ are highest for lignite coals. Higher amounts of moisture released from lignite generates hydroxyl radicals which promote the oxidation of carbon, and are probably the source of the higher concentrations of $\mathrm{CO}$ and $\mathrm{CO}_{2}$. Anthracite, because of its lowest moisture content, by the same token produces the lowest $\mathrm{CO}$ and $\mathrm{CO}_{2}$ concentrations. The minimum $\mathrm{O}_{2}$ concentration, an indicator of the oxygen consumption rate and the extent of exothermic oxidative reactions, is lowest in the lifted flame after the first transition with the addition of bituminous coal. It may be attributed to the fact that the generation of more volatiles in the core retards the inward diffusion of oxygen to the coal particles and reduces the rate of heterogeneous kinetics. It also makes the homogeneous reaction slow in the flame core because the additional volatiles make the local fuel-air mixture too rich to burn. Consequently, oxygen concentration builds up in this axial region with bituminous coal flames.

\subsection{Radiation emission from the flame stabilization region}

Figure 8 shows a comparison of radiation emission from the flame base region of the gas jet flames seeded with different coals. As expected, the addition of coal increases the radiation emission level from the flame base. The variation of radiation with flame configurations is similar with and without coal seeding. Radiation emission increases after the first transition and decreases slightly after the second transition. The peak value of radiation emission is highest for bituminous coal $\left(1200 \mathrm{~W} / \mathrm{m}^{2}\right)$. The volatiles in bituminous coal contain a large fraction of soot producing heavy hydrocarbons. The large amount of soot produced is the cause of the highest radiation from bituminous coal seeded flame. The devolatilization of lignite produces a large amount of $\mathrm{H}_{2} \mathrm{O}$ and promotes the oxidation of pyrolysis fragments and reduces the concentration of condensed species. As the condensed species contribute a major fraction of the thermal radiation, because of their continuous emission over all wavelength spectra, the radiation emission form lignite is lower than that from the bituminous coal seeded flame. Anthracite has the lowest volatile content and thus produces the lowest amount of soot and energy release in the flame base region, and thus yields the lowest radiation from the flame base.

\section{CONCLUSIONS}

With the addition of pulverized coal to gas jet flames, the behaviour of flame lift-off and reattachment are not markedly altered. With the reduction in the concentration of co-fired gas, the flame lifts off the burner and stabilizes at a higher level. The flame base appears laminar, having sharp and defined edges, and is spatially stable. With a further increase in the diluent content of the jet stream, the flame base shifts to a higher level into a turbulent region, and the flame base fluctuates in space. The reattachment process exhibits 


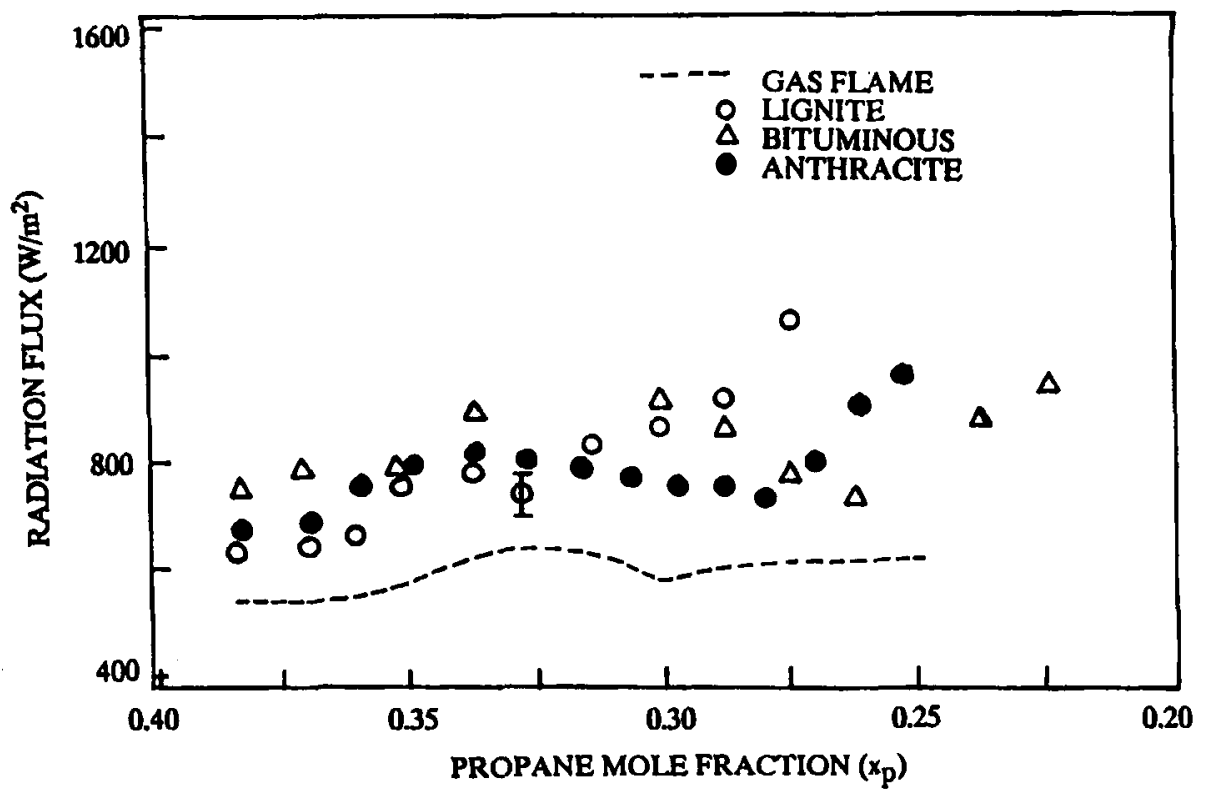

Fig. 8 Radiation emission from the base region of gas and pulverized coal seeded gas flames

hysteresis in both pure gas jet and pulverized coal seeded flames. The addition of lignite and anthracite coals favours the lift-off transitions. Bituminous coal, on the other hand, makes the flame more stable. The peak values of temperature and concentrations of major combustion product species in the flame stabilization region strongly depend upon the rank of coal. Among the coals tested, bituminous coal produces the highest peak temperature and its flame emits maximum radiation from the stabilization region. Anthracite and lignite coals produce somewhat comparable stability characteristics and structure of the flame base. The differences in the stability and flame structure characteristics are explained by the volatile matter, moisture and pyrolysis temperature of coals.

\section{ACKNOWLEDGEMENTS}

The authors acknowledge the financial support of the US Department of Energy and the Oklahoma Mining and Mineral Resources Institute.

\section{REFERENCES}

1 Green, A. E. S. Co-Combustion '93. International Power Generation Conference, Kansas City, Kansas, ASME FACT-17, 1993, pp. 149-164.

2 Makansi, J. Co-combustion: burning biomass, fossil fuels. Power, July $1987,11-18$.

3 Green, A. E. S., Wagner, C., Saltiel, C. and Jackson, M. Pollution prevention and institutional incineration. Proceedings of Conference on Solid waste processing, Detroit, Michigan, 1992, pp. 17-20.

4 Green, A. E. S. (Ed.) Medical waste incineration and pollution prevention, 1992, pp. 1-36 (Van Nostrand Reinhold, New York).

5 Karim, G. A. and Moore, N. P. W. Examination of rich mixture operation of a dual fuel engine. In Gaseous fuels and other alternatives, Publication SP-832, 1990, pp. 55-62 (Society of Automotive Engineers, Warrendale, Pennsylvania).

6 Green, A. E. S. (Ed.) Coal burning issues, 1980, pp. 1-380 (University of Florida Press, Gainsville, Florida).
7 Green, A. E. S. and Pamidimukkala, K. M. Alternative to oil; burning coal with gas, 1981, pp. 1-140 (University of Florida Press, Gainsville, Florida).

8 Green, A. E. S. and Pamidimukkala, K. M. Synergistic combustion of coal with natural gas. Energy, 1984, 9, 477-484.

9 Janica, J. and Peters, N. Prediction of turbulent jet diffusion flame lift-off using PDF transport equation. Ninetcenth International Symposium on Combustion, The Combustion Institute, Pittsburgh, Pennsylvania, 1982, pp. 367-374.

10 Wierzba, I., Kar, K. and Karim, G. A. An experimental investigation of blowout limits of a jet diffusion flame in co-flowing streams of different velocity and composition. J. Energy Resour. Technol., $1993,115,142-147$.

11 Kalghatgi, G. T. Blowout stability of gaseous jet diffusion flames. Combust. Sci. Technol., 1981, 26, 233-239.

12 Takahashi, F. and Goss, L. P. Near-field turbulent structures and local extinction of jet diffusion flames. Twenty-fourth International Symposium on Combustion, Pittsburgh, Pennsylvania, 1992, pp. 351-359.

13 Gollahalli, S. R., Savas, O., Huang, R, and Rodriguez Azara, J. L. Structure of attached and lifted gas jet flames in hysteresis region. Twenty-first International Symposium on Combustion, Pittsburgh, Pennsylvania, 1986, pp. 1463-1471.

14 Prasad, A., Gundavelli, S. and Gollahalli, S. R. Characteristics of diluent-caused lifted gas jet flames. J. Propulsion and Power, 1991, 7, 659-667.

15 Satyaraj, S. P. and Gollahalli, S. R. A laboratory scale study of sulfur dioxide emission from combustion of pulverized coal blends. Emerging Energy Technology Symposium, ASME PD-36, 1990, pp. 7-14.

16 Kopparthi, V. and Gollahalli, S. R. Nitric oxide emission from pulverized coal blend flames. J. Energy Resour. Technol., 1995, 117, 228-233.

17 Gollahalli, S. R., Prasad, A. and Gundavelli, S. Combustion of pulverized coal blends. Research report OU-AMNE-88-3, 1988.

18 Fristrom, R. M. and Westenberg, A. A. Flame structure, 1965 (McGraw-Hill Publications, New York).

19 Kanury, A. M. Introduction to combustion phenomena, 1975 (Gordon and Breach Publications, New York).

20 Hertzberg, M., Cashdollar, K. and Lazzara, C. P. The limits of flammability of pulverized coals and other dusts. Eighteenth International Symposium on Combustion, The Combustion Institute, Pittsburgh, Pennsylvania, 1981, pp. 717-727.

21 Glassman, I. Combustion principles, 1987 (Academic Press, London).

22 Bradley, D., Dixon-Lewis, G. and El-Din Habik, S. Lean flammability and laminar burning velocities of $\mathrm{CH}_{4}$-air-graphite mixtures and fine coal dusts. Combust. and Flame, 1989, 77, 41-50. 
23 Savas, O. and Gollahalli, S. R. Flow structure in the near-nozzle region of gas jet flames. Am. Inst. Aeronaut. Astronaut. J., 1986, 24 $1137-1140$.

$24 \mathrm{Kim}$, S. J. and Shin, H. D. A visual study of the structure of turbulent nonpremixed flames near jet exit. Combust. Sci. Technol., $1994,99,37-49$.

25 Butuk, N. and Gollahalli, S. R. Particle effects on shear layers ASME/AIAA Oklahoma Symposium, Stillwater, Oklahoma, 1995.

26 Gundavelli, S. Stability and structure of pulverized coal seeded gas jet flames. MS thesis, University of Oklahoma, Norman, Oklahoma, 1989.
27 Seeker, W. R., Samuelson, G. S., Heap, M. P. and Trollinger, J. D. The thermal decomposition of pulverized coal particles. Eighteenth International Symposium on Combustion, The Combustion Institute, Pittsburgh, Pennsylvania, 1981, pp. 1213-1226.

28 Melean, W. J., Hardesty, D. R. and Pohl, J. Direct observations of devolatilizing pulverized coal particles in a combustion environment. Eighteenth International Symposium on Combustion, The Combustion Institute, Pittsburgh, Pennsylvania, 1981, pp. 12391248 . 